\title{
The face mask as an established symbol against COVID-19
}

\author{
(D) Ose Medina Pestana,,2, \\ Doberto Carmagnani Pestana ${ }^{3}$
}

1. Coordenador, Força-Tarefa do Estado do São Paulo contra o Coronavírus, São Paulo, SP, Brasil. 2. Divisão de Nefrologia, Hospital do Rim Fundação Oswaldo Ramos, UNIFESP, São Paulo, SP, Brasil. 3. Centro de Oncologia e Hematologia Família Dayan-Daycoval, Hospital Israelita Albert Einstein, São Paulo, SP, Brasil.

The COVID-19 pandemic is often described as a state of war'. However, military conflicts take place in defined geographic areas, even when designated as a world war. On the other hand, SARS-COV-2 spread from the city of Wuhan to every continent in a few months. Similarly to warfare, almost every social activity was compromised, leading to economic and social stagnation in most affected areas. However, while war is permeated by the hope for a peace treaty that will clear the trenches, the viral pandemic will not have a sharp stop after an agreement; it will languish slowly and gradually, without a brisk end, leaving behind bereavement and exhaustion.

With over 32 million infected people and more than 990 thousand deaths, the campaign against COVID-19 needs a symbol of protection analogous to an armor. In this context, the universal use of face masks earns this connotation, by covering almost the entire area susceptible to the "bullet", i.e., the virus, and representing the commitment to defend our superior respiratory tract ${ }^{2}$. Face masks create a mechanical barrier to our constant manipulation of the oral and nasal mucosa, and the discomfort promoted by its conscious use acts as a permanent reminder of the transmission risk.

The unusual visuals produced by a face mask further impose social distancing, which is also paramount for safety in restarting economic and social activities. Masks provide protection when the possibility of contagion or transmission is high such as in the presence of respiratory symptoms, as cough or sneezes. Face masks also lower the risk in the presence of pre-symptomatic or asymptomatic carriers, especially when distancing is kept, and physical contact is minimized ${ }^{3}$.

In the history of pandemics, perhaps the most conflicting tasks are those related to reopening, due to the lack of established parameters that would allow for unquestionable decisions. It is important to notice that most protocols for a safe reopening place too much emphasis on the potential role of inanimate objects or surfaces in spreading the disease $\mathrm{u}^{4}$. Ultimately, hand washing and avoiding manipulation of the airway are more effective to contain viral spread than obsessively cleaning surfaces and objects. 
Moreover, increasing awareness for strategies to decrease contagion within households is critical, as studies show a high rate of domiciliary SARS-COV-2 transmission. In any location, it is important to be cognizant about the risk of infection, which incites the need for protection ${ }^{5}$, reminding that the small discomfort of wearing a face mask is not comparable to that of a ventilator in an intensive care unit.

\section{Author's Contribution}

All authors made substantial contributions to all aspects of the preparation of this manuscript.

\section{REFERENCES}

1 Maxwell, D. N., Perl, T. M. \& Cutrell, J. B. "The Art of War" in the Era of Coronavirus Disease 2019 (COVID-19). Clin Infect Dis, ciaa229, doi:10.1093/ cid/ciaa229 (2020).

2 Leung, N. H. L. et al. Respiratory virus shedding in exhaled breath and efficacy of face masks. Nature Medicine 26, 676-680, doi:10.1038/s41591020-0843-2 (2020).

3 Bai, Y. et al. Presumed Asymptomatic Carrier Transmission of COVID-19. JAMA 323, 1406-1407, doi:10.1001/jama.2020.2565 (2020).

4 Goldman, E. Exaggerated risk of transmission of COVID-19 by fomites. Lancet Infect Dis, S1473-3099(1420)30561-30562, doi:10.1016/S14733099(20)30561-2 (2020).

5 Wang, Y. et al. Reduction of secondary transmission of SARS-CoV-2 in households by face mask use, disinfection and social distancing: a cohort study in Beijing, China. BMJ Global Health 5, e002794, doi:10.1136/bmjgh2020-002794 (2020). 